\title{
Jurnal

\section{STRATEGI UNTUK MENGATASI KEPADATAN UNIT GAWAT DARURAT (UGD): TINJAUAN PUSTAKA}

\section{Strategies for Coping with Overcrowded Emergency Department (ED): Literature Review}

\author{
Rosmini Rasimin ${ }^{1,2}$, Yuliana Syam ${ }^{1}$, Rosyidah Arafat ${ }^{1}$, Sintawati Majid ${ }^{3}$
}

1. Magister of Nursing Hasanuddin University, Indonesia

2. RSUP. Dr. Wahidin Sudirohusodo, Indonesia

3. ETN Centre Indonesia, Indonesia

\section{Riwayat artikel}

Diajukan: 22 Januari 2021

Diterima: 1 Maret 2021

\section{Penulis Korespondensi:}

- Rosmini Rasimin

- Universitas Hasanuddin

e-mail:

rosminiminy83@gmail.co

$\mathrm{m}$

Kata Kunci:

Kepadatan Unit Gawat

Darurat, , Strategi

\section{Abstrak}

Pendahuluan : Unit gawat darurat (ED) sebagai pintu gerbang penanganan awal pasien dengan kegawatdarutatan berisiko mengalami Kepadatan Tujuan: literature review ini adalah untuk mencari strategi yang tepat untuk mengatasi kepadatan di ED. Metode : yang digunakan yaitu pencarian pada electronic database seperti Pubmed, DOAJ, dan google scholar, menggunakan kata kunci Crowding AND Emergency Department, awal ditemukan 1160 artikel,15 artikel dimasukkan setelah melalui proses screening, adapun artikel yang dipilih dari database dalam rentang tahun 2013-2019. Hasil : review menyajikan penyebab kepadatan di ED, alat ukur, efek yang ditimbulkan, dan srategi penanganan kepadatan di ED. kepadatan ED menyebabkan banyak kerugian sehingga dibutuhkan aplikasi yang dapat meminimalisir dampak lamanya waktu tunggu di UGD Kesimpulan : lama tinggal dan keterlambatan pemeriksaan penunjang mempengaruhi kepadatan, system informasi serta pengelompokan pasien dapat menurunkan kepadatan, National Emergency Department Overcrowding Scale (NEDOCS) direkomendasikan untuk mengukur skala kepadatan di ED.

\section{Abstract}

Background : Emergency Department (ED) as the gateway for initial handling of patients with emergency at risk of congestion. The purpose of this literature review is to find the right strategy to overcome overcrowding in the ED. Objective: used is searching for electronic databases such as Pubmed, DOAJ, and google scholar, using the keyword Crowding AND Emergency Department, initially found 1160 articles, 15 articles were entered after going through the screening process Method : design uses is quantitative descriptive. 214 respondents was used on this research by total sampling technique. Results : of the review present the causes of density in the ED, measuring instruments, its effects, and density management strategies in the ED. ED density causes a lot of losses so that an application is needed that can minimize the impact of the long waiting time in ED. Conclusion : length of stay and delay in investigations affect overcrowding, information systems and immediate action can reduce overcrowding, the National Emergency Department Overcrowding Scale (NEDOCS) is recommended to measure the density scale in the ED. 


\section{PENDAHULUAN}

Emergency department (ED) merupakan pintu gerbang saat pasien masuk ke rumah sakit. Pada tahun 2012 terdapat 131 juta kunjungan pada unit gawat darurat di Amerika Serikat dimana 14,5 juta (11\%) diterima di ED (US Department of Heatlh \& Human Services, 2013). Sistem Informasi Departemen Darurat Nasional di Korea Selatan mencatat bahwa terdapat 4,97 juta kunjungan di ED di tahun 2012, sebanyak 995.326 kasus yang masuk ke ED (20\%), dimana sekitar $14 \%$ dirawat di unit perawatan intensif (National Emergency Medical Center, 2013). ED adalah respons medis garis depan terhadap setiap bencana namun, pada saat ini di AS itu sudah melampaui batasnya.

ED berfungsi menerima, menstabilkan dan mengatur pasien yang membutuhkan penanganan kegawatdaruratan segera, baik dalam kondisi sehari-hari maupun bencana, sehingga sudah menjadi hal yang biasa jika ED merupakan tempat tersibuk dan terpadat di dalam RS. Berdasarkan Keputusan Menteri Kesehatan RI tahun 2009 menyatakan bahwa data kunjungan masuk pasien ke ED di Indonesia adalah 4.402.205 pasien (13.3\%) dari total seluruh kunjungan di rumah sakit umum. Peningkatan akses masyarakat memanfaatkan fasilitas ED sebanding dengan peningkatan jumlah kunjungan pasien sehingga mengakibatkan ED berada dalam kondisi overcrowded atau kepadatan pasien dengan segala konsekuensinya sekaligus menjadi masalah krisis nasional dan internasional (Kundiman et al., 2019).

Ruang lingkup praktik dalam penanganan gawat darurat terdiri dari beberapa tahap mulai dari waktu observasi yang cukup lama, pemeriksaan diagnostik secara kompleks, dan peningkatan perawatan kritis serta perawatan intensif di ED. Kondisi tersebut dapat memicu ED menjadi padat dan terasa sesak setiap harinya karena terkadang satu pasien menghabiskan lebih banyak waktu di ED untuk menerima perawatan definitif dan pemeriksaan penunjang diagnostik lainnya sebagai prosedur sebelum pasien dipindahkan ke ruang perawatan (McKenna et al., 2019). Kepadatan di IGD telah muncul dalam beberapa tahun terakhir sebagai masalah internasional, dengan laporan crowding di Amerika Utara, Eropa, Asia, Afrika, dan Australia. Ini adalah masalah keamanan pasien utama yang terkait dengan hasil pasien yang buruk, peningkatan Length of Stay (LOS), keterlambatan untuk triase dan perawatan, yang dapat mengancam keselamatan pasien. hal ini seharusnya menjadi perhatian besar berbagai pihak ditinjau dari IGD sebagai salah satu gerbang masuk pasien. oleh karena itu review literature ini bertujuan untuk mengidentifikasi penyebab, dampak, dan strategi yang dapat dilakukan untuk mengatasi masalah kepadatan di ED .

\section{METODE}

Metode yang digunakan dalam review literature ini adalah dengan menganalisis artikel - artikel yang ditemukan yang terkait dengan kepadatan di setting emergency department. Pencarian artikel dilakukan pada lebih dari satu data base, yang pertama yaitu pada data base pubmed dengan menggunakan kata kunci Crowding (Title/Abstract) menemukan 12.096 artikel, kemudian dilanjutkan dengan kata kunci yang kedua yaitu emergency department (Title/Abstract) dan menemukan 265.371 artikel, selanjutnya dilakukan komparasi untuk meningkatkan spesifisitas kata kunci yaitu crowding AND emergency department menghasilkan 97 artikel. Data based kedua yang digunakan adalah DOAJ dengan menggunakan kata kunci crowding dan menemukan 1543 artikel, kemudian dilanjutkan dengan kata kunci yang kedua yaitu emergency department dan menemukan 26.043 artikel, dan selanjutnya dilakukan juga komparasi kata. kunci yaitu crowding AND emergency department dan menghasilkan 14 artikel. Dan dari google schoolar menggunakan kata kunci crowding 
menemukan 728.000 artikel, kemudian dilanjutkan dengan kata kunci yang kedua yaitu emergency department menemukan 3.170.000 artikel, dan selanjutnya dilakukan komparasi kata kunci yaitu crowding AND emergency department ditemukan 49 artikel. Artikel yang di review adalah artikel yang di publikasikan dalam kurun waktu 7 tahun terakhir (tahun 2013-2019) yang terkait dengan crowding pada emergency department,menggunakan bahasa inggris dan tidak terkhusus pada satu negara. Artikel dikritisi menggunakan critikal apraisal dan artikel di saring secara rinci pada diagram Prisma (Diagram.1).

\section{HASIL}

Dari penelusuran literatur pada tiga data base menghasilkan 160 artikel, setelah dilakukan screening didapatkan 102 diantaranya memiliki judul yang tidak sesuai dengan kata kunci yang dicari, 32 yang double publikasi, 11 yang tidak dapat diakses dan bukan bahasa inggris, sehingga hasil akhir dari pencarian menemukan 15 artikel yang digunakan dalan literatur review ini. Dari 15 artikel yang dianalisis, berdasarkan factor penyebab kepadatan disebutkan bahwa Lama tinggal yang lama di ED, tes laboratorium dan pencitraan tertunda, keterlambatan konsultan, dan kurangnya tempat tidur rawat inap yang cukup adalah penyebab paling penting dari kepadatan di ED(Erenler et al., 2014). Hasil penelitian lain menyebutkan LOS meningkat menyebabkan kepadatan lebih sering terjadi (Mentzoni et al., 2019). Kepadatan berkaitan dengan LOS (meliputi ; waktu yang dihabiskan untuk triase, waktu tunggu untuk ruang pemeriksaan yang tersedia, waktu tunggu kedatangan penyedia layanan kesehatan, dan waktu tunggu untuk disposisi) yang lama dan

peningkatan jumlah pasien, selain itu faktor risiko independen yang mempengaruhi status crowding ED adalah jumlah total pasien, jumlah hasil menunggu pasien, jumlah pasien di ruang tunggu dan waktu tunggu terlama pasien di ruang tunggu (Wang et al., 2015)

Selain penyebab kepadatan kami juga melihat dampak dari kepadatan di ED terhadap petugas dan ketepatan tindakan. Terdapat hubungan antara kondisi overcrowded dengan ketepatan pelaksanaan triase (Kundiman et al., 2019) dimana Kemampuan melakukan triage menurun disaat yang mendesak (Ekins et al., 2015). Peningkatan Pengunjung ED juga berdampak terhadap waktu dokter-dokter spesialis yang semakin terfragmentasi(Castner \& Suffoletto, 2018) sehingga memungkinkan penaganan yang kurang maksimal.

Selanjutnya kami mengidentifikasi alat ukur kepadatan yang di gunakan, sebuah hasil penelitian versi modifikasi dari National Emergency Department Overcrowding Scale (mNEDOCS) melaporkan adanya korelasi yang kuat antara hasil dari mNEDOCS dengan kepadatan yang dirasakan oleh staf ED(Linden et al., 2018). Ada korelasi yang cukup positif antara NEDOC dan skala subjektif, dengan rho 0,58 ( $\mathrm{p}<0,001)$. NEDOCS dapat dikumpulkan dengan mudah di berbagai rumah sakit di Inggris untuk menilai variasi crowding pada rentang waktu yang panjang, tetapi kurang sensitif terhadap pengukuran per jam (Boyle et al., 2016). 4 jam mungkin merupakan interval yang paling tepat untuk menilai crowding dengan alat-alat ini, yang secara substansial dapat mengurangi beban personel ED(Wang et al., 2017). Selain NEDOCS sebuah penelitian juga menggunakan Severely overcrowded, Overcrowded and Not overcrowded Estimation Tool (SONET) sebagai alat ukur kepadatan yang reliable diantara petugas(Wang et al., 2015).

Terakhir kami mengidentifikasi strategi yang diberikan untuk penanganan kepadatan di ED. Hasil wawancara sebuah penelitian melaporkan Strategi dikaitkan pada 4 domain organisasi dengan kinerja rumah sakit antara lain keterlibatan kepemimpinan eksekutif, strategi terkoordinasi di seluruh rumah sakit, 
manajemen berbasis data, dan akuntabilitas kinerja(Chang et al., 2018). Contoh strategi rumah sakit berkinerja tinggi dalam penanganan kepadatan ED: (1) Menyediakan sumber daya untuk mencapai tujuan ini (misalnya, pembelian peralatan modal; baru dokter, perawat, dan staf tambahan),(2).Menentukan target : $80 \%$ pasien ED akan diterima atau dipulangkan dalam waktu 3 jam,(3) membeli CT baru (computed tomography) pemindai dan mesin ultrasonografi terhubung nirkabel untuk meningkatkan waktu penyelesaian radiologi (Chang et al., 2018). Di rumah sakit berkinerja tinggi, dorongan untuk perubahan dimulai dari atas. Pimpinan eksekutif rumah sakit meletakkan dasar untuk peningkatan ini, seperti perekrutan konsultan dan kepemimpinan ED baru untuk mengimplementasikan perubahan, membangun tim kepemimpinan operasional baru, dan meningkatkan kapasitas ED dan rawat inap. Sebaliknya, kepemimpinan eksekutif berkinerja rendah Rumah sakit tidak memprioritaskan inisiatif kerumunan mengetahui penyebabnya(Chang et al., 2018). Selain itu Sebuah pendekatan juga di tawarkan dalam penanganan kepadatan dimana sebuah penelitian mencoba membuat pendekatan standar untuk evaluasi kesadaran pasien dalam rangka mengurangi penerimaan rumah sakit, biaya medis, dan lama tinggal di bagian gawat darurat yang penuh sesak di rumah sakit pendidikan tersier di Korea Selatan(Shin et al., 2013).

Kami juga menemukan adanya kaitan dengan system informasi dimana system informasi juga memiliki peranan penting. dalam laporan kepadatan ,sebuah penelitian mengembangkan sebuah system informasi real-time tentang Kepadatan ED. Informasi ini memungkinkan staf ED untuk menilai apakah tindakan korektif diperlukan dalam upaya untuk menghindari efek samping dari Kepadatan ED(Martin et al., 2018). Strategi lain yang di tawarkan adalah penggunaan POCT ditemukan meningkatkan jumlahnya pasien dipulangkan tepat waktu, mempercepat triase pasien yang mendesak tetapi tidak darurat, dan mengurangi penundaan untuk memulai pengobatan. POCT bila digunakan secara efektif, dapat mengurangi dampak negatif dari kepadatan yang berlebihan pada keamanan, efektivitas, dan perawatan yang berpusat pada orang di $\operatorname{ED}$ (Rooney \& Schilling, 2014).

\section{DISKUSI}

Beberapa penyebab dari kepadatan di ED dikaitkan dengan peningkatan jumlah pasien, LOS yang meningkat, Pemeriksaan yang tertunda menyebabkan waktu tunggu yang lama, keterlambatan petugas / pemeriksa dan juga jumlah tempat tidur yang tersedia. hal ini sejalan dengan beberapa laporan yang melaporkan beberapa penyebab dari kepadatan di ED adalah kurangnya staf/tenaga, tempat tidur pasien rawat inap belum memadai dan permintaan jumlah pasien pengguna ED yang meningkat (Chang et al., 2018; Higginson \& Boyle, 2018; Martin et al., 2018; McKenna et al., 2019; Zocchi MS, McClelland MS, 2015). Kepadatan juga sering terjadi akibat LOS pasien yang berhari-hari dimana seharusnya hanya sehari menjadi tiga hari (Bekmezian \& Chung, 2012; Huang et al., 2010; Krall et al., 2014; L et al., 2012; White et al., 2013).jika dikaitkan dengan penilaian kinerja ED melihat dari waktu tunggu dan total waktu pasien berada di ED ini jelas tidak sesuai dari yang seharusnya dimana ukuran maksimal pasien berada di ED hanya 4 jam mengingat ada risiko pasien. akan dipulangkan terlalu cepat atau dirawat prematur sebagai pasien rawat inap, yang paling penting dapat menyebabkan kualitas perawatan yang buruk dan yang terakhir dapat memberikan tekanan di tempat lain di rumah sakit (Gunal \& Science, 2014).

Selain dampak terhadap petugas dan penurunan kinerja, disebutkan bahwa ketepatan triase di waktu yang mendesak berisiko pada ketidak tepatan penilaian. Ketidaktepatan penilaian triase memiliki resiko meningkatkan angka keselamatan pasien dan kualitas dari layanan kesehatan (Ekins, Clinical, Rn, \& Morphet, 2015). Selain itu ED yang terlalu padat ataupun 
overcrowding akan menimbulkan beberapa masalah lain dalam pelayanan, diantaranya konsekuensi yang harus diterima terkait biaya perawatan maupun biaya pengobatan pasien meningkat, keterlambatan dalam perawatan untuk semua pasien, termasuk pasien kritis, Centers for Disease Control and Prevention menemukan terdapat $10 \%$ di antara pasien yang menunggu lebih dari satu jam untuk dapat bertemu dengan dokter (Mortal \& Rep, 2003). Sebuah studi tahun 2009 menemukan bahwa dampak dari kepadatan yang terjadi di ED menimbulkan peningkatan 3-5 kali lipat komplikasi penyakit lebih serius pada pasien sindrom koroner akut (Pines et al., 2009). Studi lain yang dilakukan di tahun 2012 menunjukkan bahwa kepadatan di ED meningkatkan angka kematian 28 hari pada pasien pneumonia yang ditemukan dari komunitas/masyarakat (Jo et al., 2012). Kepadatan di ED juga sering mendapatkan kasus dimana sejumlah pasien yang pergi tanpa terlihat oleh staf, beberapa diantara mereka bahkan ada yang sedang menderita penyakit serius (Richardson \& Bryant, 2004; Weiss et al., 2005). ED yang terlalu padat juga sering menimbulkan insiden kesalahan medis dan mengurangi kualitas perawatan yang diberikan oleh staf akibat kewalahan dalam melayani pasien dengan jumlah yang banyak (Kulstad et al., 2010; Liu et al., 2009; Weissman et al., 2007). Sebuah aplikasi telah dikembangkan dalam mengatasi kepadatan di ED melalui pengukuran tingkat kepadatan di ED sehingga hasil dari pengukuran tersebut dapat menentukan rencana selanjutnya yang akan dilaksanakan.

Alat untuk mengukur crowding IGD sebenarnya ada beberapa diantaranya NEDOCS, SICMED, dan ERWIN. Bahkan sebuah penelitian menyatakan bahwa baik SICMED dan NEDOCS dapat digunakan dengan mudah di berbagai rumah sakit di Inggris, namun perlu studi lebih lanjut, untuk mempelajari kedua skor karena keduanya mungkin memiliki potensi digunakan untuk menilai variasi crowding pada rentang waktu yang lama, tetapi kurang sensitif terhadap variasi yang setiap jam (Boyle et al., 2016). Pengukuran kepadatan di rumah sakit biasanya dilakukan dengan menghitung secara keseluruhan RS, padahal setiap dari unit RS memiliki kepadatan yang berbeda sehingga butuh alat ukur yang objektif dan akurat serta valid untuk digunakan pada setiap unit pelayanan. Salah satu alat crowding ED yang paling umum digunakan adalah National Emergency Department Overcrowding Scale (NEDOCS). NEDOCS pada awalnya dikembangkan sesuai dengan interval pengukuran 4 jam, tetapi penelitian selanjutnya menggunakan interval pengukuran crowding mulai dari 1 hingga 4 jam (Wang et al., 2017). NEDOCS merupakan alat ukur yang valid dan akurat dalam memprediksi tingkat kepadatan di pusat-pusat akademik (Weiss et al., 2002), Evaluasi crowding ED dengan menggunakan NEDOCS telah divalidasi, mudah digunakan dan digeneralisasikan, hal ini ditemukan setelah dilakukan pengujian pada tiga fasilitas rumah sakit dengan berbagai pengaturan, selain itu alat ukur ini tingkat akurasinya tinggi secara objektif. dan berkorelasi sempurna dengan persepsi staf ED (Jobé et al., 2017). Oleh karena itu, aplikasi NEDOCS dalam mengukur tingkat kepadatan di ED dapat

Kepadatan di ED dapat mengurangi kualitas, kuantitas, dan konsistensi pelayanan serta perawatan yang akan diberikan (Castner \& Suffoletto, 2018). Dampak lain dari kepadatan yang tejadi di ED adalah waktu tunggu untuk bertemu dengan dokter lebih lama, pasien lebih lama dirawat, dan timbul rasa ketidakpuasan pasien terhadap pelayanan (Hwang et al., 2011). Selain itu, kepadatan juga menyebabkan kurang tepatnya petugas kesehataan dalam melakukan triase (Kundiman et al., 2019). Menurut chang paparan terhadap kondisi ED yang padat yang sangat berbahaya dikaitkan dengan peningkatan mortalitas jangka pendek, keterlambatan dalam perawatan, dan pengalaman pasien yang lebih buruk (Chang et al., 2018). Besarnya efek dari 
Overcrowding adalah sekitar 13 kematian per tahun (Richardson, 2006), oleh karena itu tujuan dari review literature ini adalah untuk mengetahui penyebab, alat ukur, efek yang ditimbulkan, dan srategi penaganan kepadatan di ED sehingga selanjutnya dapat menjadi dasar dalam melakukan penanganan kepadatan ED. Chang dalam penelitiannya juga mengatakan bahwa diperlukan pemahaman strategi yang efektif dalam mengurangi.

\section{Referensi}

Bekmezian, A., \& Chung, P. (2012). Boarding admitted children in the emergency department impacts inpatient outcomes. Pediatric Emerg Care, 28(42), 236.

Boyle, A., Abel, G., Raut, P., Austin, R., Dhakshinamoorthy, V., Ayyamuthu, R., Murdoch, I., \& Burton, J. (2016). Comparison of the International Crowding Measure in Emergency Departments ( ICMED ) and the National Emergency Department Overcrowding Score ( NEDOCS ) to measure emergency department crowding : pilot study. 307312. https://doi.org/10.1136/emermed2014-203616.

Castner, J., \& Suffoletto, H. (2018). Emergency Department Crowding And Time At The Bedside: A Wearable Technology Feasibility Study. Journal of Emergency Nursing. https://doi.org/10.1016/j.jen.2018.03.005

Chang, A. M., Cohen, D. J., Lin, A., Augustine, J., Handel, D. A., Howell, E., Kim, H., Pines, J. M., Schuur, J. D., McConnell, K. J., \& Sun, B. C. (2018). Hospital Strategies for Reducing Emergency Department Crowding: A Mixed-Methods Study. Annals of Emergency Medicine, 71(4), 497-505.e4.

https://doi.org/10.1016/j.annemergmed .2017.07.022

Ekins, K., Clinical, G., Rn, N., \& Morphet, J. (2015). The accuracy and consistency of rural, remote and outpost triage nurse decision making in one Western Australia Country Health Service Region. Australasian Emergency Nursing Journal. https://doi.org/10.1016/j.aenj.2015.05.00 2.

Erenler, A. K., Akbulut, S., Guzel, M., Cetinkaya, H., Karaca, A., Turkoz, B., \& Baydin, A. (2014). Reasons for overcrowding in the emergency department: Experiences and suggestions of an education and research hospital. Turkiye Acil Tip Dergisi, 14(2), 59-63. https://doi.org/10.5505/1304.7361.2014. 48802.

Gunal, M. M., \& Science, N. (2014). Understanding Accident and Emergency Department Performance using Simulation. Winter Simulation Conference, December 2006. https://doi.org/10.1109/WSC.2006.3231 14.

Higginson, I., \& Boyle, A. (2018). What should we do about crowding in emergency departments? British Journal of Hospital Medicine, 79(9), 500-503. https://doi.org/10.12968/hmed.2018.7 9.9.500

Huang, Q., Thind, A., Dreyer, J., \& Zaric, G. (2010). The impact of delays to admission from the emergency department on inpatient outcomes. BMC Emerg Med, 10, 16.

Hwang, U., Mccarthy, M. L., Aronsky, D., Asplin, B., Crane, P. W., Craven, C. K., Epstein, S. K., Fee, C., Handel, D. A., Pines, J. M., Rathlev, N. K., Schafermeyer, R. W., Zwemer, F. L., \& Bernstein, S. L. (2011). Measures of Crowding in the Emergency Department: A Systematic Review. The Society for Academic Emergency Medicine, 527538. $\quad$ https://doi.org/10.1111/j.15532712.2011.01054.x.

Jo, S., Kim, K., \& Lee, J. (2012). Emergency department crowding is associated with 28-day mortality in community-acquired pneumonia patients. $J$ Infect, 64(75), 268 
Jobé, J., Donneau, A., \& Scholtes, B. (2017). Quantifying emergency department crowding: comparison between two scores. Acta Clinica Belgica, 3286(December), $\quad 1-6$. https://doi.org/10.1080/17843286.2017.1 $\underline{41060}$

Krall, S., Cornelius, A., \& Addison, J. (2014). Hospital factors impact variation in emergency department length of stay more than physician factors. West $J$ Emerg Med, 15(64), 158.

Kulstad, E., Sikka, R., Sweis, R., Kelley, K., \& Rzechula, K. (2010). ED overcrowding is associated with an increased frequency of medication errors. Am J Emerg Med, 28(9), 304.

Kundiman, V., Kumaat, L., \& Kiling, M. (2019). Hubungan Kondisi Overcrowded Dengan Ketepatan Pelaksanaan Triase Di Instalasi Gawat Darurat Rsu Gmim Pancaran Kasih Manado. E-Journal Keperawatan (e-Kp), 7, 1-7.

L, Y., Zhou, G., He, X., Shen, W., Gan, J., \& Zhang, M. (2012). M. Prolonged length of stay in the emergency department in high-acuity patients at a Chinese tertiary hospital. EMA Emergency Medicine Australasia, 24(40), 634.

Linden, M. C. Van Der, Loon, M. Van, Gaakeer, M. I., Richards, J. R., Derlet, R. W., \& Linden, N. Van Der. (2018). A di ff erent crowd, a di ff erent crowding level? The prede fi ned thresholds of crowding scales may not be optimal for all emergency departments. Elsevier, May.

https://doi.org/10.1016/j.ienj.2018.05.00 $\underline{4}$.

Liu, S., Stelfox, H. T., Gordon, J., Hamedani, A., \& Weissman, J. (2009). A pilot study examining undesirable events among emergency department-boarded patients awaiting inpatient beds. Ann Emerg Med, 54(5), 381.

Martin, N., Bergs, J., Eerdekens, D., Depaire, B., \& Verelst, S. (2018). Developing an emergency department crowding dashboard: A design science approach. International Emergency Nursing, $\quad 39, \quad 68-76$. https://doi.org/10.1016/j.ienj.2017.08. 001.

McKenna, P., Heslin, S. M., Viccellio, P., Mallon, W. K., Hernandez, C., \& Morley, E. J. (2019). Emergency department and hospital crowding: Causes, consequences, and cures. Clinical and Experimental Emergency Medicine, 6(3), 189-195. https://doi.org/10.15441/ceem.18.022

Mentzoni, I., Bogstrand, S. T., \& Faiz, K. W. (2019). Emergency department crowding and length of stay before and after an increased catchment area. BMC Health Services Research, 19(1), 1-11. https://doi.org/10.1186/s12913-0194342-4.

Mortal, M. M., \& Rep, W. (2003). Quickstarts: percentage of emergency department visit with waiting time for a physician of $>1$ hour, by racelethnicity and triage level.

National Emergency Medical Center. (2013). 2012 Yearbook of emergency medical statistics (Internet). Seoul: National Emergency Medical Center

Pines, J., Pollack, C. J., Diercks, D., Chang, A., Shofer, F., \& Hollander, J. (2009). The association between emergency department crowding and adverse cardiovascular outcomes in patients with chest pain. Academic Emergency Medicine, 16(25), 617.

Richardson, D. B. (2006). Increase in patient mortality at 10 days associated with emergency department overcrowding. 184(5).

Richardson, D. B., \& Bryant, M. (2004). Confirmation of association between overcrowding and adverse events in patients who do not wait to be seen. Academic Emergency Medicine, 11, 462

Rooney, K. D., \& Schilling, U. M. (2014). Point-of-care testing in the overcrowded emergency department can it make a difference? 1-7. 
https://doi.org/10.1186/s13054-0140692-9

Shin, T. G., Kim, J. S., Song, H. G., Jo, I. J., Sim, M. S., \& Park, S. (2013). Standardized Approaches to Syncope Evaluation for Reducing Hospital Admissions and Costs in Overcrowded Emergency Departments. 54(5), 1110 1118.

US Department of Heatlh \& Human Services. (2013). National hospital ambulatory medical care survey: 2012 emergency department summary tables (Internet). Atlanta GA; Centers for Disease Control and Prevention

Wang, H., Ojha, R. P., Robinson, R. D., Jackson, B. E., Shaikh, S. A., Cowden, C. D., Shyamanand, R., Leuck, J., Schrader, C. D., \& Zenarosa, N. R. (2017). Optimal Measurement Interval for Emergency Department Crowding Estimation Tools. Annals of

Emergency Medicine. https://doi.org/10.1016/j.annemergmed .2017.04.012

Wang, H., Robinson, R. D., Cowden, C. D., Gorman, V. A., Cook, C. D., Gicheru, E. K., Schrader, C. D., Jayswal, R. D., \& Zenarosa, N. R. (2015). Use of the SONET score to evaluate urgent care center overcrowding: A prospective pilot study. BMJ Open, 5(4).

https://doi.org/10.1136/bmjopen-2014006860

Bekmezian, A., \& Chung, P. (2012).

Boarding admitted children in the emergency department impacts inpatient outcomes. Pediatric Emerg Care, 28(42), 236.

Boyle, A., Abel, G., Raut, P., Austin, R., Dhakshinamoorthy, V., Ayyamuthu, R., Murdoch, I., \& Burton, J. (2016). Comparison of the International Crowding Measure in Emergency Departments ( ICMED) and the National Emergency Department Overcrowding Score ( NEDOCS ) to measure emergency department crowding : pilot study. 307-312. https://doi.org/10.1136/emermed-
2014-203616

Castner, J., \& Suffoletto, H. (2018).

Emergency Department Crowding

And Time At The Bedside: A

Wearable Technology Feasibility

Study. Journal of Emergency Nursing.

https://doi.org/10.1016/j.jen.2018.03.0 05

Chang, A. M., Cohen, D. J., Lin, A., Augustine, J., Handel, D. A., Howell, E., Kim, H., Pines, J. M., Schuur, J. D., McConnell, K. J., \& Sun, B. C. (2018). Hospital Strategies for

Reducing Emergency Department Crowding: A Mixed-Methods Study. Annals of Emergency Medicine, 71(4), 497-505.e4.

https://doi.org/10.1016/j.annemergmed .2017.07.022

Ekins, K., Clinical, G., Rn, N., \& Morphet, J. (2015). The accuracy and consistency of rural, remote and outpost triage nurse decision making in one Western Australia Country Health Service Region. Australasian Emergency Nursing Journal. https://doi.org/10.1016/j.aenj.2015.05. 002

Erenler, A. K., Akbulut, S., Guzel, M., Cetinkaya, H., Karaca, A., Turkoz, B., \& Baydin, A. (2014). Reasons for overcrowding in the emergency department: Experiences and suggestions of an education and research hospital. Turkiye Acil Tip Dergisi, 14(2), 59-63. https://doi.org/10.5505/1304.7361.201 4.48802

Gunal, M. M., \& Science, N. (2014). Understanding Accident and Emergency Department Performance using Simulation. Winter Simulation Conference, December 2006. https://doi.org/10.1109/WSC.2006.323 114

Higginson, I., \& Boyle, A. (2018). What should we do about crowding in emergency departments? British Journal of Hospital Medicine, 79(9), 500-503. 
https://doi.org/10.12968/hmed.2018.7 9.9.500

Huang, Q., Thind, A., Dreyer, J., \& Zaric, G. (2010). The impact of delays to admission from the emergency department on inpatient outcomes. BMC Emerg Med, 10, 16.

Hwang, U., Mccarthy, M. L., Aronsky, D., Asplin, B., Crane, P. W., Craven, C. K., Epstein, S. K., Fee, C., Handel, D. A., Pines, J. M., Rathlev, N. K., Schafermeyer, R. W., Zwemer, F. L., $\&$ Bernstein, S. L. (2011). Measures of Crowding in the Emergency Department: A Systematic Review. The Society for Academic Emergency Medicine, 527-538.

https://doi.org/10.1111/j.1553-

2712.2011.01054.x

Jo, S., Kim, K., \& Lee, J. (2012).

Emergency department crowding is associated with 28-day mortality in community-acquired pneumonia patients. J Infect, 64(75), 268.

Jobé, J., Donneau, A., \& Scholtes, B. (2017). Quantifying emergency department crowding : comparison between two scores. Acta Clinica Belgica, 3286(December), 1-6. https://doi.org/10.1080/17843286.201 7.1410605

Krall, S., Cornelius, A., \& Addison, J. (2014). Hospital factors impact variation in emergency department length of stay more than physician factors. West J Emerg Med, 15(64), 158.

Kulstad, E., Sikka, R., Sweis, R., Kelley, K., \& Rzechula, K. (2010). ED overcrowding is associated with an increased frequency of medication errors. Am J Emerg Med, 28(9), 304.

Kundiman, V., Kumaat, L., \& Kiling, M. (2019). Hubungan Kondisi Overcrowded Dengan Ketepatan Pelaksanaan Triase Di Instalasi Gawat Darurat Rsu Gmim Pancaran Kasih Manado. E-Journal Keperawatan (e$K p), 7,1-7$.

L, Y., Zhou, G., He, X., Shen, W., Gan, J.,
\& Zhang, M. (2012). M. Prolonged length of stay in the emergency department in high-acuity patients at a Chinese tertiary hospital. EMA Emergency Medicine Australasia, 24(40), 634.

Linden, M. C. Van Der, Loon, M. Van, Gaakeer, M. I., Richards, J. R., Derlet, R. W., \& Linden, N. Van Der. (2018). A di ff erent crowd, a di ff erent crowding level? The prede fi ned thresholds of crowding scales may not be optimal for all emergency departments. Elsevier, May. https://doi.org/10.1016/j.ienj.2018.05. 004

Liu, S., Stelfox, H. T., Gordon, J., Hamedani, A., \& Weissman, J. (2009). A pilot study examining undesirable events among emergency departmentboarded patients awaiting inpatient beds. Ann Emerg Med, 54(5), 381.

Martin, N., Bergs, J., Eerdekens, D., Depaire, B., \& Verelst, S. (2018). Developing an emergency department crowding dashboard: A design science approach. International Emergency Nursing, 39, 68-76. https://doi.org/10.1016/j.ienj.2017.08. 001

McKenna, P., Heslin, S. M., Viccellio, P., Mallon, W. K., Hernandez, C., \& Morley, E. J. (2019). Emergency department and hospital crowding: Causes, consequences, and cures. Clinical and Experimental Emergency Medicine, 6(3), 189-195. https://doi.org/10.15441/ceem.18.022 Mentzoni, I., Bogstrand, S. T., \& Faiz, K. W. (2019). Emergency department crowding and length of stay before and after an increased catchment area. BMC Health Services Research, 19(1), 1-11. https://doi.org/10.1186/s12913019-4342-4

Mortal, M. M., \& Rep, W. (2003). Quickstarts: percentage of emergency department visit with waiting time for a physician of > 1 hour, by racelethnicity and triage level. 
National Emergency Medical Center. (2013). 2012 Yearbook of emergency medical statistics (Internet). Seoul: National Emergency Medical Center.

Pines, J., Pollack, C. J., Diercks, D., Chang, A., Shofer, F., \& Hollander, J. (2009). The association between emergency department crowding and adverse cardiovascular outcomes in patients with chest pain. Academic Emergency Medicine, 16(25), 617.

Richardson, D. B. (2006). Increase in patient mortality at 10 days associated with emergency department overcrowding. 184(5).

Richardson, D. B., \& Bryant, M. (2004). Confirmation of association between overcrowding and adverse events in patients who do not wait to be seen. Academic Emergency Medicine, 11, 462.

Rooney, K. D., \& Schilling, U. M. (2014).

Point-of-care testing in the overcrowded emergency department can it make a difference? 1-7. https://doi.org/10.1186/s13054-0140692-9

Shin, T. G., Kim, J. S., Song, H. G., Jo, I. J., Sim, M. S., \& Park, S. (2013). Standardized Approaches to Syncope Evaluation for Reducing Hospital Admissions and Costs in Overcrowded Emergency Departments. 54(5), 1110 1118.

US Department of Heatlh \& Human Services. (2013). National hospital ambulatory medical care survey: 2012 emergency department summary tables (Internet). Atlanta GA; Centers for Disease Control and Prevention.

Wang, H., Ojha, R. P., Robinson, R. D., Jackson, B. E., Shaikh, S. A., Cowden, C. D., Shyamanand, R., Leuck, J., Schrader, C. D., \& Zenarosa, N. R. (2017). Optimal Measurement Interval for Emergency Department Crowding Estimation Tools. Annals of
Emergency Medicine.

https://doi.org/10.1016/j.annemergmed .2017.04.012

Wang, H., Robinson, R. D., Cowden, C. D., Gorman, V. A., Cook, C. D., Gicheru, E. K., Schrader, C. D., Jayswal, R. D., \& Zenarosa, N. R. (2015). Use of the SONET score to evaluate urgent care center overcrowding: A prospective pilot study. BMJ Open, 5(4). https://doi.org/10.1136/bmjopen-2014006860

Weiss, S. J., Derlet, R., Arndahl, J., Ernst, A. A., Schwab, R., Richards, J., Ferna, M., Stair, T. O., Vicellio, P., Levy, D., Brautigan, M., Johnson, A., \& Nick, T. G. (2002). Estimating the Degree of Emergency Department Overcrowding in Academic Medical Centers : Results of the National ED Overcrowding Study ( NEDOCS ). April, 38-50. https://doi.org/10.1197/S10696563(03)00583-9

Weiss, S. J., Ernst, A. A., Derlet, R., King, R., Bair, A., \& Nick, T. G. (2005). Relationship between the National ED Overcrowding Scale and the number of patients who leave without being seen in an academic ED. Am J Emerg Med, 23(94), 288.

Weissman, J., Rothschild, J., \& Bendavid, E, et al. (2007). Hospital workload and adverse events. Med Care, 45(55), 448

Weissman, J., Rothschild, J., \& Bendavid, E, et al. (2007). Hospital workload and adverse events. Med Care, 45(55), 448.

White, B., Biddinger, P., Chang, Y., Grabowski, B., Carignan, S., \& Brown, D. (2013). Boarding inpatients in the emergency department increases discharged 44(5), 230 patient length of stay. JEmerg Med, 